\title{
Effect of the Surrounding Polymers of a Polymer Radical on Its Termination Rate
}

\author{
Katsukiyo ITO \\ Government Industrial Research Institute, \\ Nagoya, Hiratemachi, 1-chome, Kita-ku, Nagoya 462, Japan.
}

(Received May 27, 1981)

\begin{abstract}
An effect of the surrounding polymers of a polymer radical on its termination rate has been studied in the radical polymerization of methyl methacrylate. The surrounding polymers were prepared by prepolymerization at a temperature $T$ during time $t$. After $t$, the temperature was changed to $T^{*}$ and the polymerization was continued to obtain the kinetic data. When the chain length $\bar{n}$ of the surrounding polymers was smaller than that $\bar{n}^{*}$ of the polymer radical, termination rate was found to be $\bar{k}_{\mathrm{t}} \propto 1 / \bar{n}$ at $\bar{n} \leq \bar{n}_{\mathrm{c}}$ and $\bar{k}_{\mathrm{t}}=$ const. at $\bar{n}>\bar{n}_{\mathrm{c}}$ where $\bar{n}_{\mathrm{c}} \simeq 300$ $c^{-2}$ (c, polymer concentration). When $\bar{n}>\bar{n}^{*}, \bar{k}$ is independent of $\bar{n}$. On the basis of the above results, the onset of the gel effect is defined to be the point at which $\bar{k}_{\mathrm{t}}$ changes abruptly at $\bar{n}_{\mathrm{c}}$. This point was found explicitly to be the critical conversion at which $\bar{n}-x$ curve ( $x$, conversion) and $\bar{n}_{\mathrm{c}}$ cross each other.
\end{abstract}

KEY WORDS Concentrated Polymer Solution / Temperature Changing Method / Polymer Radical / Termination Rate / Gel Effect /

In order to treat kinetics in radical polymerization, evaluation of the termination rate between polymer radicals is necessary. When conversion is above a few percent in bulk polymerization, the excluded volume effect on the rate becomes negligibly small, and the rate constant for termination may be described as, ${ }^{1,2}$

$$
\bar{k}_{\mathrm{t}}=\frac{4 \pi p R D}{1+p}
$$

where $R$ is the encounter distance between polymer radicals, $D$, the relative translational diffusion coefficient of polymer, and $p$, the specific rate at distance $R$ and is derived as,

$$
p=\frac{4 \pi R_{\mathrm{S}} D_{\mathrm{S}}}{4 \pi R D}
$$

where $R_{\mathrm{S}}$ is the reaction radius between segment radicals and $D_{\mathrm{S}}$ is the relative diffusion coefficient of the segments. When $p \ll 1$, eq 1 becomes,

$$
\overline{k_{\mathrm{S}}}=4 \pi R_{\mathrm{s}} D_{\mathrm{S}}
$$

following modification of this equation by introducing the excluded volume effect and considering the effect of translational diffusion on the motion of a segment, it was used to treat the experimental data obtained at low conversion. ${ }^{3,4}$ At a high conversion, $R$ might approach $R_{\mathrm{S}}\left(p \rightarrow D_{\mathrm{S}} / D \gg 1\right)$, so that eq 1 reduces,

$$
\bar{k}_{\mathrm{T}}=4 \pi R_{\mathrm{S}} D
$$

After $D$ in this equation was evaluated by Stokes' law and reputation theory, eq 4 was applied to the experimental data at high conversion. ${ }^{5}$ Equation 1 may thus be rewritten as eq 5 , in terms of eq 3 and 4 .

$$
\frac{1}{\bar{k}_{\mathrm{t}}}=\frac{1}{\bar{k}_{\mathrm{S}}}+\frac{1}{\bar{k}_{\mathrm{T}}}
$$

where $\bar{k}_{\mathrm{T}}=4 \pi R D$ and eq 5 becomes eq 4 when $R \rightarrow R_{\mathrm{S}}$. Equation 5 is a theoretical illustration of the change in the termination rate with increasing conversion.

In the present paper, evaluation of this change by eq 5 was done by using the kinetic data based on physical meanings. These data were obtained for the bulk polymerization of methyl methacrylate (MMA) initiated by 2,2'-azobisisobutyronitrile (AIBN) in the presence of nonreactive PMMA of various chain lengths. 


\section{EXPERIMENTAL}

Commercial MMA and AIBN were purified by the method described above. ${ }^{6}$

The initiator and monomer in the ampoule were degassed under a vacuum of about $10^{-3} \mathrm{mmHg}$. The ampoule was maintained at a given temperature $T$ during the proper prepolymerization time $t$ in order to prepare the surrounding polymers of a polymer radical. Following the lapse of time $t$, the temperature was changed to $T^{*}$ and the polymerization was continued during the proper time $t^{*}$ to obtain kinetic data. Here, the chain length of the surrounding polymers was estimated by measuring the intrinsic viscosity $[\eta]=8.12 \times 10^{-3} \tilde{n}^{0.71}$ in toluene at $25^{\circ} \mathrm{C} .^{7}$

Formerly in preparing the surrounding polymers, the polymers of short chain length were dissolved in the polymerization solution. ${ }^{8-10}$ However, the preparation of a uniform high concentration solution of polymers of the proper chain length was difficult, as stated in ref 10. By the temperature changing method in the present paper, we were able to prepare the polymerization solution of an arbitrary concentration of polymers having the proper chain length and in which the maximum of $\dot{n}$ was determined by the transfer of the polymer radical to the monomer and polymer. To assist in carrying out this method, polymers with $\bar{n}=168$ and 424 were also prepared and used as the surrounding polymers of a polymer radical.

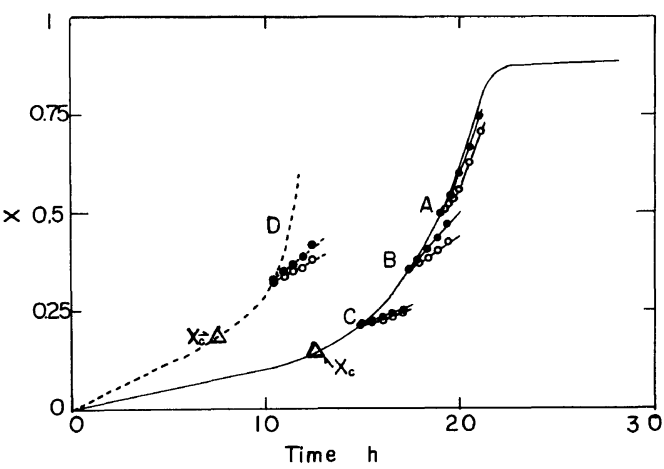

Figure 1. Time-conversion curves in polymerizations when of $\bar{n}^{*}>\bar{n}$ at $T=30.0^{\circ} \mathrm{C}:---,[\mathrm{C}]_{0}=0.152 \mathrm{~mol} \mathrm{dm}^{-3}$; ,$-[\mathrm{C}]_{\circ}=0.0305 ; \mathrm{A}, x^{*}=0.50 ; \mathrm{B}, x^{*}=0.36 ; \mathrm{C}, x^{*}=0.21$; $\mathrm{D}, x^{*}=0.33\left(\mathrm{O}, T^{*}=90.0^{\circ} \mathrm{C} ; 0,80.0\right)$.

\section{RESULTS}

When the temperature was not changed $\left(T=T^{*}\right.$ or $\left.t^{*}=0\right)$, the usual converson-time $(x-t)$ curve was obtained (Figures 1 and 2). When the temperature was changed from 80 and $90^{\circ} \mathrm{C}$ to $30^{\circ} \mathrm{C}, x^{*}-t^{*}$ curves were obtained and are shown in Figure 1.

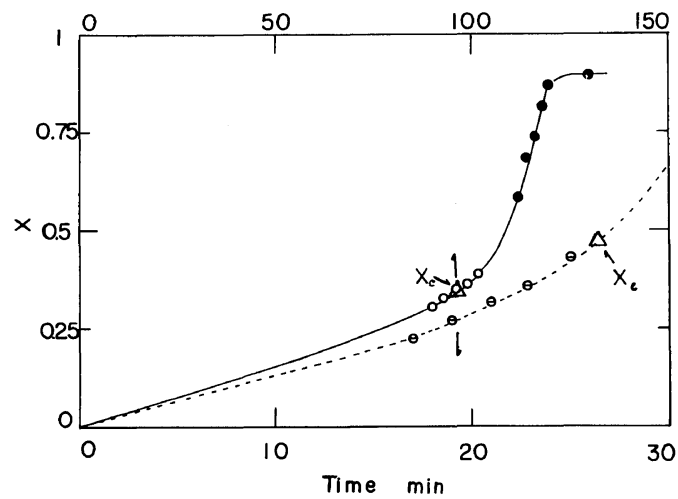

Figure 2. Time-conversion curves in polymerizations in which $\bar{n}^{*}<\bar{n}:-, T^{*}=60.0^{\circ} \mathrm{C}\left(\bigcirc, x^{*}=0.305 ; \bigcirc, x^{*}=\right.$ 0.584 at $T=30.0^{\circ} \mathrm{C}$ at $\left.[\mathrm{C}]_{\circ}=0.0305 \mathrm{~mol} \mathrm{dm}^{-3}\right) ;---, T^{*}=$ $80.0\left(\ominus, x^{*}=0.225\right.$ at $T=30.0$ at $\left.[C]_{\circ}=0.0305\right)$.

Table I. Kinetic data obtained at $[C]_{\circ}=0.0305 \mathrm{~mol} \mathrm{dm}^{-3}$ at $T^{*}=30.0^{\circ} \mathrm{C}^{\mathrm{a}}$

\begin{tabular}{|c|c|c|c|c|}
\hline$T$ & \multirow{2}{*}{$x_{\circ}^{*}$} & $10^{5} R_{\mathrm{p}}$ & $10^{-5} \bar{k}$ & \multirow{2}{*}{$\bar{n}$} \\
\hline${ }^{\circ} \mathrm{C}$ & & \multicolumn{2}{|c|}{$\mathrm{mol} \mathrm{dm} \mathrm{m}^{-3} \mathrm{~s}^{-1} \mathrm{dm}^{3} \mathrm{~mol}^{-1} \mathrm{~s}^{-1}$} & \\
\hline 30.0 & 0 & 2.06 & 774 & 22300 \\
\hline 30.0 & 0.210 & 9.05 & 28.7 & 32900 \\
\hline 40.0 & 0.209 & 9.04 & 28.7 & 11030 \\
\hline 50.0 & 0.210 & 8.51 & 31.9 & 7010 \\
\hline 60.0 & 0.207 & 6.63 & 51.6 & 3710 \\
\hline 70.0 & 0.214 & 5.01 & 87.3 & 2880 \\
\hline 80.0 & 0.210 & 3.80 & 143 & 1600 \\
\hline 90.0 & 0.215 & 3.30 & 186 & 780 \\
\hline 30.0 & 0.360 & 16.7 & 6.07 & 54000 \\
\hline 60.0 & 0.363 & 16.7 & 5.74 & 3950 \\
\hline 70.0 & 0.358 & 15.9 & 6.05 & 3200 \\
\hline 80.0 & 0.357 & 12.9 & 8.46 & 1510 \\
\hline 90.0 & 0.361 & 7.42 & 23.4 & 647 \\
\hline 30.0 & 0.500 & 23.6 & 2.06 & 82600 \\
\hline 60.0 & 0.495 & 23.6 & 1.93 & 10200 \\
\hline 70.0 & 0.508 & 22.1 & 2.06 & 5300 \\
\hline 80.0 & 0.503 & 20.8 & 2.12 & 2200 \\
\hline 90.0 & 0.498 & 17.2 & 2.70 & 1055 \\
\hline
\end{tabular}

a The suffix $\left({ }_{0}\right)$ denotes the initial stage. 
Table II. Kinetic data obtained at $T^{*}=30.0^{\circ} \mathrm{C}^{\mathrm{a}}$

\begin{tabular}{cccccr}
\hline $10^{3}[\mathrm{C}]$ & $T$ & $x_{\circ}{ }^{*}$ & $10^{5} R_{\mathrm{p}}$ & $10^{-5} \overline{k_{\mathrm{t}}}$ & $\bar{n}$ \\
\hline 152 & 30.0 & 0 & 6.52 & 775 & 10500 \\
152 & 30.0 & 0.330 & 34.3 & 7.74 & 24400 \\
152 & 40.0 & 0.327 & 34.2 & 7.79 & 8220 \\
152 & 50.0 & 0.333 & 29.6 & 10.3 & 3810 \\
152 & 60.0 & 0.324 & 17.7 & 28.4 & 1610 \\
152 & 70.0 & 0.332 & 12.7 & 54.4 & 862 \\
152 & 80.0 & 0.330 & 10.1 & 83.3 & 459 \\
152 & 90.0 & 0.335 & 5.2 & 300 & 230 \\
76 & 30.0 & 0.330 & 26.0 & & \\
30.5 & 30.0 & 0.330 & 16.4 & & 40500 \\
7.6 & 30.0 & 0.330 & 9.3 & & \\
\hline
\end{tabular}

a The same units as in Table I.

Table III. Kinetic data obtained at $[C]_{0}=0.0305 \mathrm{~mol} \mathrm{dm}^{-3}$ when $\bar{n}^{*}<\bar{n}^{\mathrm{a}}$

\begin{tabular}{cccccr}
\hline$T$ & $T^{*}$ & $x_{\circ}{ }^{*}$ & $10^{5} R_{\mathrm{p}}$ & $10^{-5} \bar{k}_{\mathrm{t}}$ & \multicolumn{1}{c}{$\bar{n}$} \\
\hline 30.0 & 80.0 & 0.225 & 263 & 303 & 30500 \\
80.0 & 80.0 & 0.225 & 246 & 302 & 1500 \\
30.0 & 60.0 & 0.305 & 84.4 & 92.3 & 37000 \\
60.0 & 60.0 & 0.305 & 82.5 & 91.9 & 4350 \\
30.0 & 60.0 & 0.584 & 652 & 6.9 & 93500 \\
60.0 & 60.0 & 0.584 & 642 & 6.9 & 6700 \\
\hline
\end{tabular}

a The same units as in Table I.

Table IV. Kinetic data obtained at $30.0^{\circ} \mathrm{C}$ when PMMA with a known chain length were dissolved $^{\mathrm{a}}$

\begin{tabular}{ccccc}
\hline $10^{3}[\mathrm{C}]$ & $x$ & $\bar{n}$ & $10^{5} R_{\mathrm{p}}$ & $10^{-5} \overline{k_{\mathrm{t}}}$ \\
\hline 30.5 & 0.36 & 168 & 4.0 & 105 \\
30.5 & 0.50 & 168 & 9.2 & 10.7 \\
30.5 & 0.50 & 424 & 13.4 & 6.4 \\
7.61 & 0.50 & 424 & 5.56 & \\
1.90 & 0.50 & 424 & 2.78 & \\
0.476 & 0.50 & 424 & 1.51 & \\
\hline
\end{tabular}

a The same units as in Table I.

When the temperature was changed from $30^{\circ} \mathrm{C}$ to 60 and $80^{\circ} \mathrm{C}, x^{*}-t^{*}$ curves were obtained as shown in Figure 2. The polymerization rate $R_{\mathrm{p}}$ was calculated from the slope of $x^{*}-t^{*}$ line obtained at the initial stage following the change in temperature (Tables I, II, and III). The data obtained when the polymers of $\bar{n}=168$ and 424 were dissolved are shown in Table IV.
Termination rate constant was calculated by,

$$
\bar{k}_{\mathrm{t}}=\frac{2 f k_{\mathrm{d}} k_{p}{ }^{2}[\mathrm{C}][\mathrm{M}]^{2}}{R_{\mathrm{p}}{ }^{2}}
$$

where $f$ is the fraction of a primary radical escaping from the solvent cage $(f=0.57),{ }^{9} k_{\mathrm{d}}$ is the decomposition rate constant of AIBN $\left(k_{\mathrm{d}}=1.58 \times 10^{15} \times\right.$ $\left.\exp (-15500 / T) \mathrm{s}^{-1}\right),{ }^{11} k_{\mathrm{p}}$ is propagation rate cons$\operatorname{tant}\left(k_{\mathrm{p}}=4.92 \times 10^{5} \exp (-2192 / T) \mathrm{dm}^{3} \mathrm{~mol}^{-1}\right.$, $\left.\mathrm{s}^{-1}\right),{ }^{12}$ and $[\mathrm{C}]$ and $[\mathrm{M}]$ are the concentration of the initiator and monomer, respectively. The $\bar{k}_{\mathrm{t}}$-values obtained are shown in Tables I to IV.

\section{DISCUSSION}

\section{Polymerization Carried Out When the Chain Length of Polymer Radical is Larger than $\dot{n}$}

As shown in Tables I and II, $\bar{n}$ decreases with increasing $T$. Usually, the chain length $\bar{n}^{*}$ of a polymer radical is estimated by,

$$
\bar{n}^{*}=\frac{R_{\mathrm{p}}}{2 f k_{\mathrm{d}}[\mathrm{C}]+C_{\mathrm{tr}} R_{\mathrm{p}}}
$$

where $C_{\mathrm{tr}}$ is the relative transfer constant. In consideration of this, it is evident that $\tilde{n}^{*}$ increases with increasing in $R_{\mathrm{p}}$. At $30^{\circ} \mathrm{C}, \bar{n}^{*}>22300$ at $[\mathrm{C}]=0.0305$ $\mathrm{mol} \mathrm{dm}{ }^{-3}$ and $\tilde{n}^{*}>10500$ at $[\mathrm{C}]=0.152$, as expected, because of an increase in $R_{\mathrm{p}}$ with increasing $x$ (Figure 1). Therefore, in all the polymerizations shown in Figure 1 and Tables I, II, and IV, $\bar{n}^{*}>\bar{n}$ is satisfied. When $\bar{n}$ is less than the critical chain length $\dot{n}_{\mathrm{c}}$ at a given concentration, $\bar{k}_{\mathrm{t}}$ decreases with increasing in $\bar{n}$. When $\dot{n}$ is larger than $\bar{n}_{\mathrm{c}}, \bar{k}_{\mathrm{t}}$ is independent of $\bar{n}$. These relationships are presented as follows,

$$
\begin{array}{lll}
\bar{k}_{\mathrm{t}} \propto 1 / n & \text { at } & \bar{n} \leq \bar{n}_{\mathrm{c}} \\
\bar{k}_{\mathrm{t}}=\mathrm{constant} & \text { at } & \bar{n}>\bar{n}_{\mathrm{c}}
\end{array}
$$

This phenomenon resembles a well known phenomenon in the translational diffusion of polymers, which has been treated by the classical entanglement theory ${ }^{13}$ and the modern reputation theory. ${ }^{14}$ Based on these theories, the critical chain length $n_{\mathrm{c}}$ is estimated to be,

$$
n_{\mathrm{c}}=300 c^{-\gamma}
$$

where 300 is the critical chain length in undiluted PMMA,${ }^{13} c$ is the polymer concentration, and $\gamma$ is estimated to be $1,1.25$, and $2 .{ }^{13-16}$ In the present 


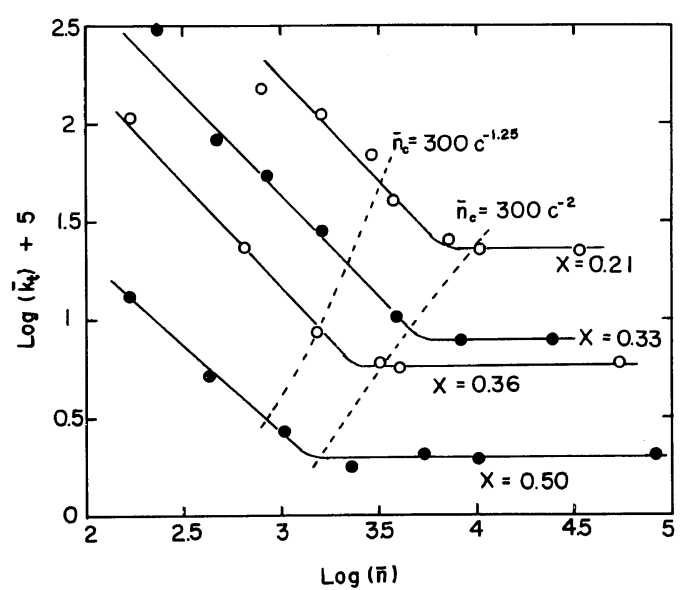

Figure 3. Relationships between $\bar{k}_{\mathrm{t}}$ and $\bar{n}$ when $\bar{n}^{*}>\bar{n}$ at $30.0^{\circ} \mathrm{C}$.

experiments, $\bar{n}_{\mathrm{c}}$ is close to eq 9 with $\gamma=1.25$ and 2 (Figure 3) and $\gamma=2$ is somewhat better. Thus, $n_{\mathrm{c}}=$ $300 c^{-2}$ is used in the following discussion.

At $\bar{n}<n_{\mathrm{c}}$, the proportionality of $\bar{k}_{\mathrm{t}}$ to $1 / \bar{n}$ (eq $8 \mathrm{a}$ ) is also obtained on the physical grounds that $\eta D_{\mathrm{s}}$ (for eq 3) or $\eta D$ (eq 4) $=$ constant and $\eta \propto \bar{n},{ }^{13}$ where $\eta$ is the solution viscosity. However, determining which one is ture, eq 3 or 4 , eq 8 a has no effect. This is based on experimental data to be presented in a later section.

At $\cdot \bar{n}>n_{\mathrm{c}}$, the termination rate derived as eq 4 corresponds to eq $8 \mathrm{~b}$. Since the diffusion coefficient of polymer is proportional to the entanglement density, eq 4 shows that the entanglement density is independent of the chain length of the surrounding polymers.

\section{Polymerization in Which $\bar{n}^{*}<\bar{n}$}

In the polymerizations shown in Figure 2 and Table III, the condition of $\bar{n}^{*}<\bar{n}$ is satisfied. The polymerization rate whose temperature was changed $\left(T=30^{\circ} \mathrm{C} \rightarrow T^{*}=60\right.$ or 80$)$, was slightly larger than $R_{\mathrm{p}}$, whose temperature was not changed. This slight difference is based on the difference in [C], $k_{\mathrm{d}}$ which increases with change in temperature. When the difference in $[\mathrm{C}]$ is modified, the respective difference in $[\mathrm{C}][\mathrm{M}]^{2} / R_{\mathrm{p}}{ }^{2}\left(\propto \bar{k}_{\mathrm{t}}\right)$ can not be detected (Table III). It is concluded that the termination rate is independent of $\bar{n}$ when $\bar{n}^{*}<\bar{n}$.

Graessely ${ }^{17}$ has discussed the complexity of the diffusion of a polymer in a polydispersity system. Although the radical polymerization system is essen- tially polydispersity, the diffusion of a polymer radical in terms of $\bar{k}_{\mathrm{t}}$ is not as complex as he maintains. At least, in the present cases, in treating diffusion of a polymer radical, the introduction of eq 8 is necessary, but the others are trivial.

\section{Definition of the Onset of the Gel Effect}

Formerly, a termination rate was presented in terms of a critical conversion at which the solution exhibited an abrupt change in viscosity. ${ }^{18}$ In particular, such a change is marked when the autoacceleration of polymerization rate appears. Thus, in order to join a quantitative understanding of this autoacceleration, the onset of the gel effect is defined by the close packing theory. ${ }^{19}$ Also Dionisio et $a l .{ }^{20}$ defined the onset of the gel effect as the point at which the segmental diffusion-controlled termination rate is equal to the translational rate $\left(\bar{k}_{\mathrm{S}}=\right.$ $\left.\bar{k}_{\mathrm{T}}\right)$. However, the above treatments do not stem from the familiar physical bases shown by eq 8 and 9. Furthermore, after the excluded volume effect has disappeared, both $\bar{k}_{\mathrm{S}}$ and $\bar{k}_{\mathrm{T}}$ decrease slowly with increasing $x$ at $\bar{n} \leq \bar{n}_{\mathrm{c}}$. Therefore, the critical convesion $x_{\mathrm{c}}$ at the onset of the gel effect is vague, when the $x-t$ curve does not change abruptly. These cases are the bulk polymerization at a lower initiation rate in Figure $1\left([\mathrm{C}]=0.0305 \mathrm{~mol} \mathrm{dm}^{-1}\right.$ at $\left.30^{\circ} \mathrm{C}\right)$ and that at high temperature $\left(80^{\circ} \mathrm{C}\right)$ as shown in Figure 2.

In the present paper, the best definition for the onset of the gel effect is made by eq 9 . That is, the onset of the gel effect is the point at which $\vec{k}_{\mathrm{t}}$ changes abruptly at $\tilde{n}_{\mathrm{c}}$. The value of $x_{\mathrm{c}}$ at this point

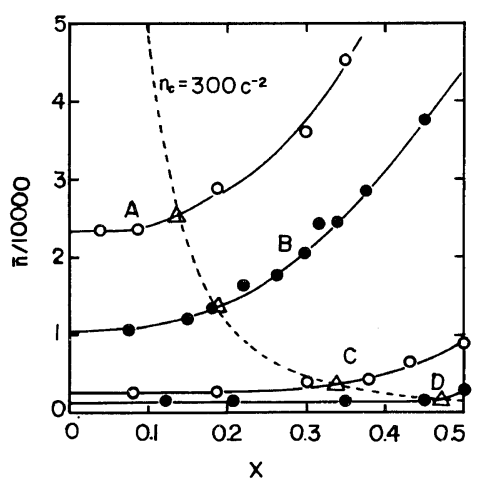

Figure 4. Determination of the critical conversion $x_{\mathrm{c}}$ $(\triangle)$ : $\mathrm{A}, x_{\mathrm{c}}=0.13$ at $30.0^{\circ} \mathrm{C}$ at $[\mathrm{C}]_{\circ}=0.0305 \mathrm{~mol} \mathrm{dm}^{-3} ; \mathrm{B}$, $x_{\mathrm{c}}=0.19$ at $30.0^{\circ} \mathrm{C}$ at $[\mathrm{C}]_{0}=0.152 ; \mathrm{C}, x_{\mathrm{c}}=0.34$ at $60.0^{\circ} \mathrm{C}$ at $[\mathrm{C}]_{0}=0.0305 ; \mathrm{D}, x_{\mathrm{c}}=0.47$ at $80.0^{\circ} \mathrm{C}$ at $[\mathrm{C}]_{\circ}=0.0305$. 
can be found explicitly as the cross point between $\bar{n}-$ $x$ curve and eq 9 (Figure 4). The $x_{c}$ values are shown in Figures 1 and 2. It is appearent that $x_{\mathrm{c}}$ corresponds to the onset of the gel effect.

\section{Dependence of $R_{\mathrm{p}}$ on $[\mathrm{C}]$}

At $x>0.1$, the excluded volume effect has disappeared. ${ }^{23}$ When $\bar{n}^{*}$ is larger than 1000 , the effect of $D$ on $D_{\mathrm{S}}$ also disappears. ${ }^{3,4}$ Thus, the termination rate does not depend on $\bar{n}^{*}$, provided it is segmentally diffusion-controlled (eq 3). However, if it is translationally diffusion-controlled (eq 4), it depends on $\dot{n}^{*}$. To clarify this, an examination of the dependence of $\bar{k}_{\mathrm{t}}$ on $\bar{n}^{*}$ is presented below. In accordance with previous reports, ${ }^{6,21}$ if the termination rate is defined as $k_{\mathrm{t}} \propto \bar{n}^{*-2 \mathrm{a}}$, the polymerization rate is given by,

$$
R_{\mathrm{D}} \propto[\mathrm{C}]^{A(a)}
$$

where $A(a)=(1-2 a) / 2(1-a)$ when the non-reacting polymers are produced by termination only. $A(a)=$ $(2-3 a) /(4-2 a)$ when the polymers are produced by both termination and the transfer. $A(a)=1 / 2$ when they are produced only by transer. For a typical

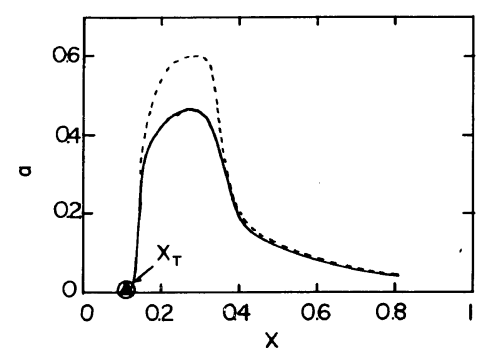

Figure 5. Relationship between $a$ and $x$ obtained in the polymerization at $45.0^{\circ} \mathrm{C}$ when $[C]_{0} \geq 0.025 \mathrm{~mol} \mathrm{dm}^{-3.6}$ -, $A(a)=(1-2 a) / 2(1-a) ;---, A(a)=(2-3 a) /(4-2 a)$.

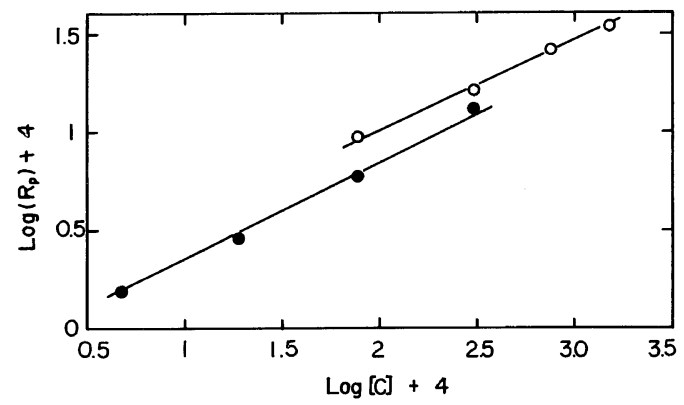

Figure 6. Relationship between $R_{\mathrm{p}}$ and $[\mathrm{C}]$ at $30.0^{\circ} \mathrm{C}$ : O, $x=0.33 ; 0, x=0.50(\bar{n}=424)$. illustration of eq 10, the relationship between $a$ and $x$ is shown in Figure 5. At $x<0.12, a$ is found to be zero. With increasing $x, a$ increases, since the termination predominates and its rate depends on $n^{*}$. At $x>0,3, a$ decreases with increasing $x$. The critical conversion $x_{\mathrm{c}}=0.13$ obtained in the polymerization at $[\mathrm{C}]_{\circ}=0.0305 \mathrm{~mol} \mathrm{dm}^{-3}$ at $30^{\circ} \mathrm{C}$ (Figure 1) is equal to the conversion $x_{\mathrm{T}}$ at which $a$ is taken off the base line. However, the other $x_{\mathrm{c}}$ values are different from $x_{\mathrm{T}}=0.12$, i.e. $x_{\mathrm{c}}=0.47$ in the polymerization at $80^{\circ} \mathrm{C}$ in Figure 2. Perhaps, at $x>x_{\mathrm{T}}$, the termination rate may be translationally diffusion-controlled and eq 4 may be used. A critical conversion defined by Dionisio et al ${ }^{20}$ may correspond to $x_{\mathrm{T}}$, since $\bar{k}_{\mathrm{S}}=\bar{k}_{\mathrm{T}}$.

In this paper, in order to estimate the long chain lenght $\bar{n}_{\mathrm{c}}=7100$ at $x=0.21$, the initiation rate at $30^{\circ} \mathrm{C}$ was made so slow that the transfer predominates at $x>0.2$. Also a higher initiation rate ([C] $>0.16 \mathrm{~mol} \mathrm{dm}^{-3}$ ) was experimentally impossible in obtaining correct kinetic data.

Consequently, as estimated from eq 7 and Tables I, II, and IV, $2 f k_{\mathrm{d}}[\mathrm{C}]<C_{\mathrm{tr}} R_{\mathrm{p}}$ may be actual at $x>0.2$, where $C_{\mathrm{tr}} \simeq 10^{-5} .{ }^{22}$ Thus, in view of eq 10 , $A(a)$ reduces to $1 / 2$, even if the termination rate depends on chain length (Figure 6). This case corresponds to the polymerization at $x>0.5$ in Figure 5.

\section{REFERENCES}

1. K. Ito, J. Polym. Sci., Polym. Chem. Ed., 10, 3159 (1972).

2. K. Ito, J. Polym. Sci., Polym. Chem. Ed., 13, 1297 (1975).

3. K. Ito, Polym. J., 11, 795 (1979).

4. K. Horie, I. Mita, and H. Kambe, Polym. J., 4, 341 (1973).

5. K. Ito, Polym. J., 12, 499 (1980); ibid., 13, 727 (1981).

6. K. Ito, J. Polym. Sci., Polym. Chem. Ed., 13, 401 (1975).

7. W. R. More and R. J. Fort, J. Polym. Sci., A, 1, 929 (1963).

8. Z. A. Rogovin and L. A. Tasplina, J. Appl. Chem. USSR (English Transl.), 20, 875 (1947).

9. B. W. Brooks, Proc. R. Soc. London Ser. A, 357, 183 (1977).

10. K. A. High, H. B. Lee, and D. T. Turner, Macromolecules, 12, 332 (1979).

11. J. Van Hook and A. Tobolsky, J. Am. Chem. Soc., 80, 779 (1958).

12. H. K. Mahabadi and K. F. O'Driscoll, J. Macromol. Sci., Chem., A11, 967 (1977).

13. N. G. Kumar, J. Polym. Sci., Macromol. Rev., 15, 
225 (1980).

14. J. Klein, Macromolecules, 11, 852 (1978).

15. F. Bueche, J. Appl. Phys., 26, 738 (1955).

16. S. Onogi, T. Kobayashi, Y. Kojima, and T. Taniguchi, J. Appl. Polym. Sci., 7, 847 (1963).

17. W. W. Graessley, J. Polym. Sci., Polym. Chem. Phys. Ed., 18, 27 (1980).

18. K. Ito, J. Polym. Sci., A-1, 7, 2707 (1969).

19. D. T. Turner, Macromolecules, 10, 221 (1977).
20. J. Dionisio, H. K. Mahabadi, K. F. O'Driscoll, E. Abuin, and E. A. Lissi, J. Polym. Sci., Polym. Chem. Ed., 12, 1991 (1979).

21. K. Ito, J. Polym. Sci., Polym. Chem. Ed., 12, 1991 (1974); ibid., 15, 1759 (1977).

22. J. Brandrup and H. Baumann, "Polymer Handbook," John Wiley \& Sons, Inc., New York, N.Y., 1966.

23. H. Yamakawa, J. Chem. Phys., 34, 1360 (1961). 